\title{
Impact of Exercise Training and Detraining on Some Hemodynamics and Inflammatory Mediators in Hypertensive Rats
}

\author{
HESHAM A.D. ABDEL-RAZEK, M.D.; SAFAA M. EL-KOTB, M.D. and MONA E.S. FARAG, M.Sc. \\ The Department of Medical Physiology, Faculty of Medicine, Menoufia University, Egypt
}

\begin{abstract}
Background: Physical exercise is suggested as a life style modification to improve hypertension.

Aim of Study: The aim of the present study was to prove that exercise training ameliorates the pathophysiology in hypertensive rats, and to investigate whether this effect is reversible after detraining.

Patients and Methods: Forty-eight adult male albino rats of local strain were used. Rats were equally divided into two main groups, normotensive and hypertensive groups. Each main group was equally divided into sedentary, exercisetrained and detrained groups ( $\mathrm{n}=8$ for each group). Hypertension was induced by subcutaneous injection of deoxy corticosterone acetate (DOCA) in a dose of $50 \mathrm{mg} / \mathrm{kg}$ body weight suspended in $0.3 \mathrm{ml}$ olive oil, once weekly for 4 weeks and drinking water with $1 \% \mathrm{NaCl}$. Rats in exercise-trained groups practiced moderate intensity treadmill exercise for 6 weeks. Rats in detrained groups practiced moderate intensity exercise for 4 weeks and remained sedentary for 2 weeks. After 6 weeks, blood samples were collected for measuring serum levels of tumor necrosis factor-alpha (TNF-a), interleukin10 (IL-10), malondialdehyde (MDA) and total antioxidant capacity (TAC). Then, systolic and diastolic arterial blood pressures were measured by invasive technique and mean arterial blood pressure (MAP) was calculated. Lastly, rats were sacrificed and heart was excised for assessing myocardial contractility (MC) and heart rate (HR) by Langendorff isolated perfused heart.
\end{abstract}

Results: Exercise training for six weeks resulted in reduction of MAP and HR and improvement of MC and all the measured biochemical parameters in hypertensive rats compared to sedentary hypertensive ones. This improvement of hypertension and cardiac performance by exercise training for six weeks is possibly by restoring the balance between pro- and anti-inflammatory cytokines, and attenuating oxidative stress. Training of hypertensive rats for four weeks and detraining for two weeks preserved the beneficial effects of exercise on MAP, TNF- $\alpha$, MDA and TAC, but the improvement was reversed in HR and IL-10.

Conclusion: Exercise detraining for two weeks did not completely lose the benefit of exercise in controlling hypertension in rats.

Correspondence to: Dr. Hesham A.D. Abdel-Razek, The Department of Medical Physiology, Faculty of Medicine, Menoufia University, Egypt
Key Words: Exercise - Hypertension - Detraining - Rats.

\section{Introduction}

HYPERTENSION is a chronic medical condition in which the blood pressure in the arteries is elevated, and is characterized by cardiac hypertrophy and dysfunction, chronic inflammation, and overactivation of the renin-angiotensin system [1]

Treatment of hypertension is considered a successful intervention to reduce cardiovascular risk Multiple blood pressure-reducing pharmaceutical approaches are in clinical use. However, recommendations for changes in lifestyle are used as the first and most promising steps leading to a reduction in blood pressure, use of blood pressure lowering medication, delay of end-organ damage and increased insulin sensitivity. These recommendations include cessation of smoking, reduction in fat and salt intake and increased physical activity [2] .

Physical activity significantly decreases the cardiovascular risk factors associated with obese individuals, cardiovascular and diabetic patients [3]. In fact, physical activity is good for health and favorably prevents most metabolic disorders, such as obesity and atherosclerosis [4]. Physical exercise has variably reduced body weight, visceral fat accumulation and blood pressure, but the main value of exercise is to allow all systems of the body to communicate much more closely than usual [5] Those who participate in an exercise regimen feel an improvement in their quality of life, leading to an enhancement in self-esteem and sense of wellbeing [6]

The present work was conducted to investigate the effect of exercise-training and detraining on blood pressure (BP), cardiac performance and some inflammatory mediators of hypertension in rats. 


\section{Patients and Methods}

The present study was conducted between November 2016 and March 2017 in Medical Physiology Department, Faculty of Medicine, Menoufia University, Egypt. It was approved by the Research Ethics Committee at Faculty of Medicine, Menoufia University.

\section{Chemicals:}

DOCA powder (Sigma, USA), Thiopental sodium $500 \mathrm{mg}$ (Sigma-Tec Pharmatheotical industries, Egypt), Elisa kits for estimation of serum TNF-ct and interleukin 10 (AssayproLLC, Saint Charles, Missouri, USA), Kits for estimation of total antioxidant capacity and serum (MDA) level (Biodiagnostic Company, Egypt), Chemicals used for preparation of krebs-Henseleit solution (Al Togaria company, Egypt), Normal saline (Nile Pharmaceutical Co, Egypt), Heparin (Amoun Pharmaceutical Co, Egypt) and Olive oil (El Watania for olive industries, Egypt).

\section{Experimental animals:}

Forty eight adult male albino rats of local strain, weighing 150-200 grams each, were used in this study. Rats were housed in standard conditions with a natural light-dark cycle and were caged in a wire mesh ventilated cages ( 8 per cage) with free access to food and water throughout the study period. Rats were equally divided into two main groups:

\section{I- Normotensive main group:}

Rats of this group received a standard rat chow diet and water ad libitum throughout the study period. They were subcutaneously (s.c.) injected with $0.3 \mathrm{ml}$ olive oil once weekly for 4 weeks, and then they were equally subdivided into the following three groups (8 animals each):

- Sedentary normotensive (N.S) group:

Normotensive rats of this group were kept sedentary (untrained) for 6 weeks.

\section{- Exercise-trained normotensive (N.Ext) group:}

Normotensive rats of this group practiced moderate-intensity exercise for 6 weeks as described below.

\section{- Detrained normotensive (N.Det) group:}

Normotensive rats of this group practiced moderate-intensity exercise of a period of 4 weeks, and then kept sedentary for the next 2 weeks [1].

\section{II- Hypertensive main group:}

Rats were made hypertensive by s.c. injection of deoxy corticosterone acetate (DOCA) in a dose of $50 \mathrm{mg} / \mathrm{kg}$ body weight (b.w.) suspended in $0.3 \mathrm{ml}$ olive oil, once weekly for 4 weeks and $1 \% \mathrm{NaCl}$ was added to their drinking water. Thereafter, they were equally subdivided into the following three groups (8 animals each):

\section{- Sedentary hypertensive (H.S) group:}

Hypertensive rats of this group were kept sedentary (untrained) for 6 weeks.

\section{- Exercise-trained hypertensive (H.Ext) group:}

Hypertensive rats of this group practiced moderate-intensity exercise for 6 weeks as described below.

\section{- Detrained hypertensive (H.Det) group:}

Hypertensive rats of this group practiced moderate-intensity exercise of a period of 4 weeks, and then kept sedentary for the next 2 weeks [1].

\section{Exercise training:}

Rats of the exercise-trained groups (N.Ext and H.Ext groups) were forced to perform moderateintensity exercise by putting them on a motordriven treadmill (5 days per week, $60 \mathrm{~min}$ per day at $18 \mathrm{~m} / \mathrm{min}, 0^{\circ}$ inclination) for 6 weeks [1] .

Rats of the detrained groups (N.Det and H.Det groups) conducted exercise under the same conditions as exercise-trained groups, but for a duration of only 4 weeks, and then they were placed on a non-moving treadmill during the next 2 weeks [1]

The rats of sedentary groups (N.S and H.S groups) were placed on a non-moving treadmill (5 days per week, $60 \mathrm{~min}$ per day) for 6 weeks.

\section{Blood sampling and biochemical assay:}

At the end of the experimental period, animals were fasted overnight and then retro-orbital blood samples were collected from the retro-orbital venous plexus, using fine heparinized capillary tubes. Two milliliters of blood were collected from each rat, and left for clotting at room temperature in a water bath for 10 minutes, and then centrifuged at 4000 rotation per minute (r.p.m.) for 10 minutes. Serum was collected and frozen at $-20^{\circ} \mathrm{C}$ till used for measurement of serum levels of tumor necrosis factor alpha (TNF- a), interleukin 10 (IL-10), malondialdehyde (MDA) and total antioxidant capacity(TAC) using their specific commercial kits according to the manufacturer instructions.

\section{Invasive measurement of arterial blood pressure:}

Thereafter, rats were subjected for measurement of arterial blood pressure (ABP) by invasive technique. Animals were anaesthetized by intraperitoneal injection of thiopental sodium (50mg/kg b.w.), 
and the aorta was identified and cannulated using a cannula pre-filled with heparinized normal saline and the other end of the cannula was connected to a three-way stopcock saline filled syringe, which was connected to a pressure transducer and the blood pressure was recorded using Physiograph system (Narco Bio-Systems, UK). The mean arterial blood pressure (MAP) was calculated from the recorded systolic and diastolic blood pressures.

\section{Heart perfusion experiment:}

Lastly, myocardial contractility and rhythmicity were measured by Langendorff technique of isolated heart perfusion.

Rats were sacrificed by cervical elongation and dislocation. The chest was quickly opened and icecold Krebs' solution, gassed with $95 \% \mathrm{O}_{2}$ and $5 \%$ $\mathrm{CO} 2$, was poured over the heart. After cutting the pericardium, the heart was delivered and the vessels to and from it were clamped with a curved artery forceps then cut alongside the forceps edge to excise the heart and its connected blood vessels. The excised heart was plunged in ice-cold Krebs' solution aerated with $95 \% \mathrm{O}_{2}$ and $5 \% \mathrm{CO}_{2}$. The heart was kept in ice-cold Krebs' solution for 2050 seconds before it was mounted to the Langendorff heart perfusion apparatus that was formed of a glass heart cannula and an isometric strain gauge transducer (Myograph F-60-H. B.S. Narco Biosystem, England, UK) to record myocardial contractility.

The aorta was cannulated by a heart cannula for coronary perfusion. The whole procedure took 1-1.5 minutes. The heart was perfused with KrebsHenseleit solution [7], which has the following composition: $6,92 \mathrm{gram} / \mathrm{L}$ of $\mathrm{NaCl}, 0.359 \mathrm{gram} / \mathrm{L}$ of $\mathrm{KCl}, 0.15 \mathrm{gram} / \mathrm{L}$ of $\mathrm{MgSO} 2,0.15 \mathrm{gram} / \mathrm{L}$ of $\mathrm{MgSO} 2,0.289 \mathrm{gram} / \mathrm{L}$ of $\mathrm{CaCl}_{2}, 2.1 \mathrm{gram} / \mathrm{L}$ of $\mathrm{NaH}$ $\mathrm{CO} 3,0.16 \mathrm{gram} / \mathrm{L}$ of $\mathrm{KH} 2 \mathrm{PO}_{4}, 2.0 \mathrm{gram} / \mathrm{L}$ of Glucose. The perfusion fluid was aerated with $95 \%$ $\mathrm{O}_{2}$ and $5 \% \mathrm{CO} 2$ and maintained at $37^{\circ} \mathrm{C}$. The heart was perfused at a controlled constant flow rate of $4.4 \mathrm{ml} / \mathrm{min}$.

\section{Statistical analysis:}

The SPSS version 16 (SPSS Inc., Chicago, IL, USA) was used for analysis of data. The results were expressed as mean \pm standard deviation (SD). The significance of differences between groups was determined by one-way analysis of variance (ANOVA) and post-hoc Tukey test was done. $p$ values $<0.05$ were considered statistically significant.

\section{Results}

\section{Biochemical parameters:}

Fig. (1) illustrates the means \pm SD of TNF- $\alpha$ and IL-10 in the different experimental groups.

A non-significant variation was seen in the serum level of TNF- $\alpha$ between N.S, N.Ext and N.Det groups $(20.67 \pm 1.57,19.35 \pm 2.26,19.65 \pm 1.78$ $\mathrm{pg} / \mathrm{ml}$, respectively). H.S group showed a significantly higher level $(51.01 \pm 2.41 \mathrm{pg} / \mathrm{ml}, p<0.05)$ than those of N.S, N.Ext and N.Det groups. In H. Ext group, the value $(23.11 \pm 2.62 \mathrm{pg} / \mathrm{ml})$ showed a significant drop $(p<0.05)$ compared to H.S group, but it was still significantly higher $(p<0.05)$ than that of N.Ext group. A non-significant change in TNF- $\alpha$ was observed between H.Ext and N.S groups. In H.Det, the TNF- $\alpha$ mean value $(24.81 \pm$ 2.25) was insignificantly different from H.Ext group, however, it was significantly less $(p<0.05)$ than that of H.S group, and significantly higher $(p<0.05)$ than those of N.S, N.Ext and N.Det groups.

Regarding IL-10, there was a non-significant variation in the serum levels of IL-10 between N.S, N.Ext and N.Det groups $(16.75 \pm 0.9,17.3 \pm$ $1.32,16.12 \pm 01.5 \mathrm{pg} / \mathrm{ml}$, respectively). H.S group showed significantly lower level $(6.43 \pm 0.88 \mathrm{pg} / \mathrm{ml}$, $p<0.05)$ compared to N.S, N.Ext and N.Det groups. In H.Ext group, the value $(10.92 \pm 1.41 \mathrm{pg} / \mathrm{ml})$ was significantly higher $(p<0.05)$ than that of H.S group, but it was still significantly lower $(p<0.05)$ than those of N.S and N.Ext groups. In H.Det, IL10 level $(7.62 \pm 1.13 \mathrm{pg} / \mathrm{ml})$ was significantly less $(p<0.05)$ than those of H.Ext, N.S, N.Ext and N.Det groups, and it was insignificantly changed from that of H.S group.

Fig. (2) illustrates the means \pm SD of MDA and TAC in the different experimental groups.

Serum levels of MDA showed insignificant difference between N.S and N.Ext groups $(2.6 \pm 0.4$ and $1.9 \pm 0.27 \mathrm{mmol} / \mathrm{L}$, respectively). MDA level was significantly higher $(p<0.05)$ in N.Det group $(3.1 \pm 0.41 \mathrm{mmol} / \mathrm{L})$, when it is compared with the corresponding value in N.Ext group, but it was insignificantly different from that of N.S group. H.S group showed a significantly higher MDA level $(7.9 \pm 1.25 \mathrm{mmol} / \mathrm{L}, p<0.05)$ than those of N.S, N.Ext and N.Det groups. The MDA level of H.Ext group was significantly decreased $(3.7 \pm 0.5 \mathrm{mmol} / \mathrm{L}$, $p<0.05)$ compared to that of H.S group, but it was still significantly higher $(p<0.05)$ than those of N.S and N.Ext groups. In H.Det group, MDA value $(4.2 \pm 0.52 \mathrm{mmol} / \mathrm{L})$ was insignificantly different 
from that of H.Ext group, but it was significantly lower $(p<0.05)$ than that of H.S group and significantly higher $(p<0.05)$ than those of N.S, N.Ext and N.Det groups.

TAC in N.Ext group $(2.3 \pm 0.44 \mathrm{mmol} / \mathrm{L})$ was significantly more $(p<0.05)$ than that of N.S group $(1.67 \pm 0.16 \mathrm{mmol} / \mathrm{L})$. In N.Det group, TAC $(1.87 \pm$ $0.18 \mathrm{mmol} / \mathrm{L}$ ) was insignificantly different from that of N.S group, but significantly less $(p<0.05)$ than that of N.Ext group. H.S group showed a significant $(p<0.05)$ decrease in TAC $(0.77 \pm 0.27$ $\mathrm{mmol} / \mathrm{L})$, when compared with those of N.S, N.Ext and N.Det groups. In H.Ext group, TAC (1.45 \pm 0.29 $\mathrm{mmol} / \mathrm{L})$ was significantly $(p<0.05)$ more than that of H.S group, but it was still significantly $(p<0.05)$ lower than that of N.Ext; a non-significant change was observed between H.Ext and N.S groups. In H.Det group, TAC $(1.11 \pm 0.2 \mathrm{mmol} / \mathrm{L})$ was insignificantly different from those of H.S and H.Ext groups, but it was significantly lower $(p<0.05)$ than those of N.S, N.Ext and N.Det groups.

Arterial blood pressure, myocardial contractility and heart rate:

The presented table demonstrates the MAP, myocardial contractility and heart rate of the different experimental groups.

The MAP levels in N.S, N.Ext and N.Det groups showed nonsignificant differences. H.S group showed significantly higher MAP level $(p<0.05)$ compared to N.S N.Ext and N.Det groups. In H.Ext group, MAP level was significantly more $(p<0.05)$ than those of N.S and N.Ext groups, but it was significantly less $(p<0.05)$ than that of H.S group.

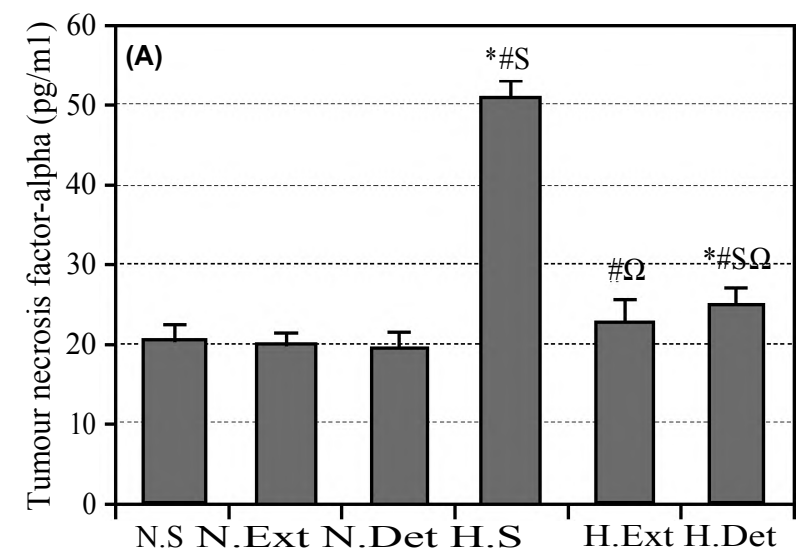

Also, in H.Det group, MAP level was significantly more $(p<0.05)$ than those of N.S, N.Ext and N.Det groups, but it was were significantly less $(p<0.05)$ than that of H.S group. A non-significant variation was observed between H.Ext and H.Det groups.

Regarding the myocardial contractility, N.Ext group showed significantly higher contractility $(p<0.05)$ than that of N.S group. In N.Det group, contractility was significantly less $(p<0.05)$ than that of N.Ext group, but it was insignificantly changed from that of N.S group. H.S group showed a significant reduction $(p<0.05)$ in contractility, when compared with the corresponding values of N.S, N.Ext and N.Det groups. In H.Ext group, contractility was significantly higher $(p<0.05)$ than that of H.S group. In H.Det group, it was insignificantly different from those of H.S and H.Ext groups. Both H.Ext and H.Det groups showed a significantly decreased contractility $(p<0.05) \mathrm{com}$ pared to those of N.S, N.Ext and N.Det groups.

Regarding the heart rate, N.Ext group showed a significantly lower rate $(p<0.05)$ than that of N.S group. In N.Det group, rate was significantly more $(p<0.05)$ than that of N.Ext group, and insignificantly different from that of N.S group. H.S group showed a significant elevation of heart rate $(p<0.05)$ compared to those of N.S, N.Ext and N.Det groups. The heart rate was significantly decreased in H.Ext group $(p<0.05)$ compared to that of H.S group. In H.Det group, the rate was significantly higher ( $p<$ 0.05 ) than that of H.Ext group, and insignificantly different from H.S group. Both H.Ext and H.Det groups showed significantly higher rates $(p<0.05)$ than those of N.S, N.Ext and N.Det groups.

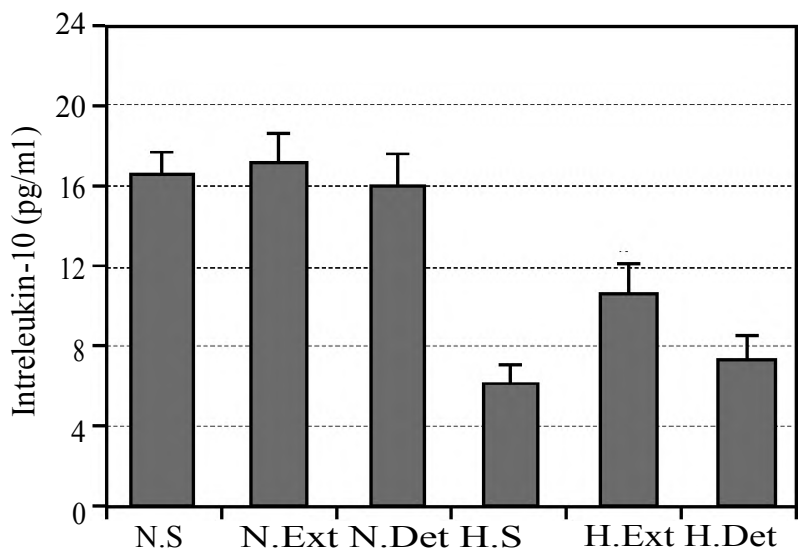

Fig. (1): Serum tumour necrosis factor-alpha (Panel A) and interleukin-10 (Panel B) levels in sedentary normotensiv (N.S), exercise-trainsive normotensiv (N.Ext), detrained normotensive (N.Det), sedentary hypertensive (H.S), exercise-trainsive normotensiv (H.Ext) and detrained hypertensive (H.Det) groups. Results are expressed as mean \pm SD ( $=8)$. Significane was considered when $p$-value was $\leq 0.5$. The marks *,\#,S, $\Omega$ and $\sum$ on top of columns indicate that values are significantly different, when compared with the corrsponding values of N.S, N.Ext, N.Det, H.S and H.Ext groups, respectively. 

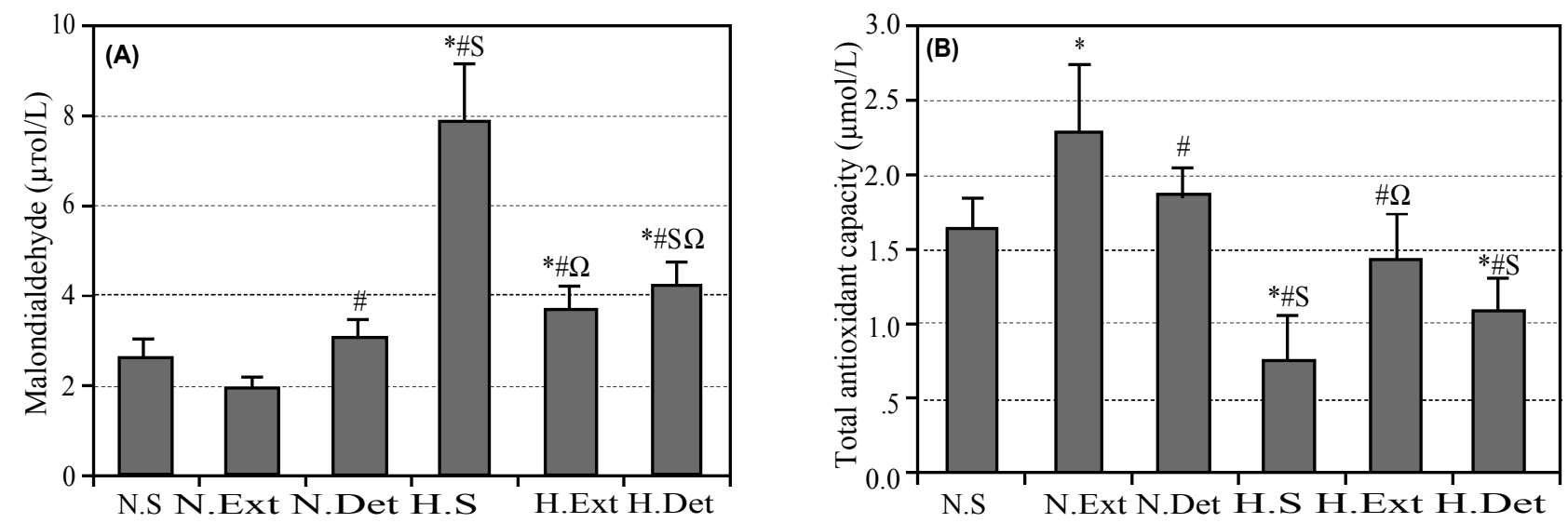

Fig. (2): Serum malondialdehyde level (Panel A) and total antioxdant capacity (Panel B) in sedentary normotensiv (N.S), exercisetrainsive normotensiv (N.Ext), detrained normotensive (N.Det), sedentary hypertensive (H.S), exercise-trainsive normotensiv (H.Ext) and detrained hypertensive (H.Det) groups. Results are expressed as mean $\pm \mathrm{SD}(\mathrm{n}=8)$. Significane was considered when $p$-value was $\leq 0.5$. The marks *,\#,S, $\Omega$ and $\sum$ on top of columns indicate that values are significantly different, when compared with the corrsponding values of N.S, N.Ext, N.Det, H.S and H.Ext groups, respectively.

Table (1): Mean arterial blood pressure (MAP), myocardial contactility and heart rate of sedentary normotensive (N.S), exercisetrained normotensive (N.Ext), detrained normotensive (N.Det), sedentary hypertensive (H. S), exercise-trained hypertensive (H.Ext) and detrained hypertensive (H.Det) groups.

\begin{tabular}{lllllll}
\hline & \multicolumn{1}{c}{ N.S } & \multicolumn{1}{c}{ N.Ext } & \multicolumn{1}{c}{ N.Det } & \multicolumn{1}{c}{ H.S } & \multicolumn{1}{c}{ H.Ext } & H.Det \\
\hline MAP (mmHg) & $103.6 \pm 4.72$ & $101.9 \pm 4.13$ & $102.7 \pm 3.53$ & $151.6 \pm 6.48 * \# \mathrm{~S}$ & $125.56 \pm 4.39 * \# \Omega$ & $126 \pm 4.29 * \# \mathrm{~S} \Omega$ \\
Myocardial contactility $(\mathrm{cm})$ & $1.6 \pm 0.22$ & $2.18 \pm 0.29 *$ & $1.7 \pm 0.18 \#$ & $0.67 \pm 0.21 * \# \mathrm{~S}$ & $1.2 \pm 0.18^{*} \Omega$ & $0.9 \pm 0.21 * \# \mathrm{~S}$ \\
Heart rate (beats/minute) & $165.3 \pm 8.24$ & $138.8 \pm 9.41 *$ & $158.6 \pm 12.38 \#$ & $267 . \pm 9.31 * \# \mathrm{~S}$ & $208.8 \pm 12.65 * \# \Omega$ & $252.1 \pm 6.33 * \# \mathrm{~S} \sum$ \\
\hline
\end{tabular}

- Results are expressed as mean $\pm \mathrm{SD}(\mathrm{n}=8)$. Significane was considered when $p$-value was $\leq 0.5$. The marks *,\#,S, $\Omega$ and $\sum$ indicate that values are significantly different, when compared with the corrsponding values of N.S, N.Ext, N.Det, H.S and H.Ext groups, respectively.

\section{Discussion}

In the present investigation, the administration of DOCA-salt $(50 \mathrm{mg} / \mathrm{kg})$ for 4 weeks resulted in significant increases of MAP, heart rate and serum levels of TNF- $\alpha$ and MDA, as well as significant decreases in myocardial contractility and serum IL- 10 level and TAC, when compared to the corresponding values in normotensive sedentary animals. DOCA-salt hypertension is thought to occur in several stages with an abrupt increase in arterial pressure during the first 48 hours followed by a delayed, slower rise in arterial pressure over the next few weeks, leading to sustained hypertension [8] . Other investigators have described a later phase, often termed malignant, where severe hypertension is observed 8-12 weeks later. There is indirect evidence that enhanced sympathetic nerve activity plays a crucial role in the development of DOCA-salt hypertension. Plasma catecholamines are elevated during the developed stage (2-6 weeks) in DOCA-salt hypertensive rats [9]. Also, the pathogenesis of DOCA-salt hypertension is dependent on non-neural mechanisms as the increased release of vasopressin and vascular responsiveness [10] In the early phase (first week), elevations in plasma sodium contribute to increasing both SNA and vasopressin release. During the subsequent developed phase of hypertension, vasopressin continues to contribute, but there is evidence that sympathetic activity is enhanced and its contribution is roughly equivalent to the humoral components, at least to some vascular beds, that are reflected in elevated plasma catecholamines. During the malignant phase, vascular restructuring and hypertrophy are also likely to contribute. Throughout the three phases, endothelin-1 levels are steadily increased and contribute more to the hypertension as it develops into the malignant phase [11].

DOCA-salt induces hypertension with cardiovascular remodeling characteristic of human volume-overload induced hypertension, especially hypertrophy, fibrosis, conduction abnormalities and endothelial dysfunction leading to heart failure [12] . This supports our results where hypertension was associated with decreased myocardial contractility and increased heart rate. Cardiovascular remodeling is induced by oxidative stress mediated by reactive free radical species and inflammation following infiltration of immune-inflammatory cells. Oxidative stress probably promotes inflam- 
mation and conversely, inflammation-induced damage promotes oxidative stress [13]. The contributions of oxidative and inflammatory stress towards the pathology and progression of cardiovascular structural remodeling have been difficult to separate. This supports our result where hypertension was associated with increased oxidative stress as evidenced by increased serum level of MDA and decreased serum level of TAC. Also, there was increased serum level of the proinflammatory cytokine, TNF- $\alpha$ and decreased serum level of the anti-inflammatory cytokine, IL-10 that evidences the presence of inflammation; an observation that was in agreement with previous studies $[\mathbf{1 4 , 1 5}]$.

In the current study, treadmill exercise training of hypertensive rats for 6 weeks ameliorates the detrimental effects of DOCA-salt hypertension as manifested by significant decreases in MAP, heart rate and serum levels of TNF- $\alpha$ and MDA, as well as significant increases in myocardial contractility and serum IL-10 level and TAC, when compared to the corresponding values in sedentary hypertensive animals. This observation was in consistency with previous studies $[\mathbf{1 , 1 6 , 1 7 ]}$. Exercise training did not return the values to the normal level as compared to sedentary normotensive animals. However, intensity, frequency, duration, and type of exercise have previously shown to affect the magnitude of the blood pressure reduction in hypertensive animals and humans $[\mathbf{1 8 , 1 9 ]}$. Exercise did not affect MAP in normotensive rats. Hypertension is characterized by chronic inflammation, which is reflected by a two- to threefold increase in circulating levels of several proinflammatory cytokines as TNF- $\alpha$ and IL- $\beta$ [20]. Additionally, anti-inflammatory cytokines, such as IL-10, have a significant impact on arterial pressure. IL-10 exerts inhibitory effects on pro inflammatory cytokines in the peripheral immune system and it has a similar role in the CNS. Over-expression of IL10 in the brain ameliorates hypertension and associated organ damage in hypertensive rats [1]. Agarwal et al., [1] recently reported that regular exercise decreases proinflammatory cytokines as TNF- $\alpha$ and upregulates IL- 10 levels in the brain of spontaneously hypertensive rats and this agrees with our results. Several studies have demonstrated excessive amounts of reactive oxygen species in essential hypertensive patients and various animal models of hypertension. These patients and experimental animals have a diminished antioxidant status, which contributes to the accumulating evidence that increased vascular oxidative stress could be involved in the pathogenesis of essential hypertension [15]. De Angelis et al., [21] reported that aerobic exercise in mice induced resting bradycar- dia, probably related to an enhancement in cardiac vagal and a decrease in cardiac sympathetic input. This agrees with our results where exercise training significantly reduced heart rate in both normotensive and hypertensive animals that practiced treadmill exercise. Moreover, Agarwal et al., [1] reported that exercise training attenuated cardiac hypertrophy and improved diastolic function in trained hypertensive animals.

The main finding in our research work was that two weeks detraining of DOCA-salt hypertensive rats did not reverse the exercise-induced reduction in MAP, whereas, detraining failed to preserve the exercise-mediated improvement in heart rate in these rats. In addition, two weeks of detraining did not have any drawbacks on exercise-induced improvement of the proinflammatory cytokine, TNF$\alpha$ in hypertensive rats, whereas, it abolished the exercise-induced improvement in the anti-inflammatory cytokine, IL-10. Moreover, detraining in exercising hypertensive rats decreased the exerciseinduced improvement of oxidative stress; an observation that was in consistency with other studies $[1,16]$.

Conclusion: Treadmill exercise training for six weeks improves hypertension and cardiac function in rats by restoring the balance between pro- and anti-inflammatory cytokines, and attenuating oxidative stress, but it does not normalize blood pressure. Two weeks of detraining partially preserved the exercise training improvement in some hemodynamics and inflammatory mediators. Further studies are needed to investigate the effect of different types and durations of exercise training and detraining on the blood pressure, cardiac performance and the inflammatory state in hypertensive animals and humans.

\section{References}

1- AGARWAL D., DANGE R.B., VILA J., OTAMENDI A.J. and FRANCIS J.: Detraining differentially preserved beneficial effects of exercise on hypertension: Effects on blood pressure, cardiac function, brain inflammatory cytokines and oxidative stress. PLoS. One, 7 (12): e52569, 2012.

2- KOKKINOS P.F. and PAPADEMETRIOU V.: Exercise and hypertension. Cornary Artery Dis, 11 (2): 99-102, 2000.

3- KADOGLOU N.P., ILIADIS F., ANGELOPOULOU N., PERREA D., AMPATZIDIS G., LIAPIS C.D. and ALEVIZOS M.: The anti-inflammatory effects of exercise training in patients with type 2 diabetes mellitus. Eur. J. Cardiovasc. Prev. Rehabil., 14 (6): 837-43, 2007.

4- PETIBOIS C., CASSAIGNE A., GIN H. and DÉLÉRIS G.: Lipid profile disorders induced by long-term cessation of physical activity in previously highly endurance-trained 
subjects. The Journal of Clinical Endocrinology \& Metabolism, 89 (7): 3377-3384, 2004.

5- LAAKSONEN D.E., LINDSTRÖM J., LAKKA T.A. and ERIKSSON J.G.: Physical activity in the prevention of type 2 diabetes: The finnish diabetes prevention study. Diabetes, 54 (1): 158-165, 2005.

6- BIRRER R.B and SEDAGHAT V.D.: Exercise and Diabetes Mellitus: Optimizing performance in patients who have type 1 Diabetes. Phys. Sports Med., 31 (5): 29-41, 2003.

7- KREBS H.A. and HENSELEIT K.: Untersuchungen uber die harnstoffbildung im tierkorper. Hoppe-seyler's zeitschrift fur. physiol. Chemie, 210: 33-66, 1932.

8- BROOKS V.L., FREEMAN K.L. and QI Y.: Time course of synergistic interaction between DOCA and salt on blood pressure: Roles of vasopressin and hepatic osmoreceptors. Am. J. Physiol. Regul. Integr. Comp. Physiol., 291 (6): R1825-R1834, 2006.

9- BOUVIER M. and de CHAMPLAIN J.: Increased basal and reactive plasma norephinephrine and epinephrine levels in awake DOCA-salt hypertensive rats. J. Auton. Nerv. Syst., 15 (2): 191-195, 1986.

10- YAMAMOTO J., YAMANE Y., UMEDA Y., YOSHIOKA T., NAKAI M. and IKEDA M.: Cardiovascular hemodynamics and vasopressin blockade in DOCA-salt hypertensive rats. Hypertension, 6 (3): 397-407, 1984.

11- YEMANE H., BUSAUSKAS M., BURRIS S.K. and KNUEPFER M.M.: Neurohumoral mechanisms in deoxycorticosterone acetate (DOCA)-salt hypertension in rats. Exp. Physiol., 95 (1): 51-55, 2010.

12- BROWN L., DUCE B., MIRIC G. and SERNIA C.: Reversal of cardiac fibrosis in deoxycorticosterone acetatesalt hypertensive rats by inhibition of the renin-angiotensin system. J. Am. Soc. Nephrol., 10 Suppl, 11: S143-148, 1999.

13- KOTLYAR E., VITA J.A., WINTER M.R., AWTRY E.H., SIWIK D.A., KEANEY J.F. Jr, SAWYER D.B., CUPPLES L.A., COLUCCI W.S. and SAM F.: The relationship between aldosterone, oxidative stress, and inflammation in chronic, stable human heart failure. J. Card. Fail., 12 (2): 122-127, 2006.
14- MA X.L., GAO F., NELSON A.H., LOPEZ B.L., CHRISTOPHER T.A., YUE T.L. and BARONE F.C.: Oxidative inactivation of nitric oxide and endothelial dysfunction in stroke prone spontaneous hypertensive rats. J. Pharmacol. Exp. Ther., 298 (3): 879-85, 2001.

15- RODRIGO R., GONZA'LEZ J. and PAOLETTO F.: The role of oxidative stress in the pathophysiology of hypertension. Hypertens. Res., 34 (4): 431-440, 2011.

16- JIA L.L., KANG Y.M., WANG F.X., LI H.B., ZHANG Y., YU X.J., QI J., SUO Y.P., TIAN Z.J., ZHU Z., ZHU G.Q. and QIN D.N.: Exercise training attenuates hypertension and cardiac hypertrophy by modulating neurotransmitters and cytokines in hypothalamic paraventricular nucleus. PLoS One, 9 (1): e85481, 2014.

17- KILIC-ERKEK O., KILIC-TOPRAK E., CALISKAN S., EKBIC Y., AKBUDAK I.H., KUCUKATAY V. and BORKUCUKATAY M.: Detraining reverses exercise-induced improvement in blood pressure associated with decrements of oxidative stress in various tissues in spontaneously hypertensive rats. Mol. Cell. Biochem., 412 (1-2): 209$219,2016$.

18- SUN M.W., QIAN F.L., WANG J., TAO T., GUO J., WANG L., LU A.Y. and CHEN H.: Low-intensity voluntary running lowers blood pressure with simultaneous improvement in endothelium dependent vasodilatation and insulin sensitivity in aged spontaneously hypertensive rats. Hypertens Res., 31 (3): 543-552, 2008.

19- CHICCO A.J., MCCUNE S.A., EMTER C.A., SPARAGNA G.C., REES M.L., BOLDEN D.A., MARSHALL K.D., MURPHY R.C. and MOORE R.L.: Low intensity exercise training delays heart failure and improves survival in female hypertensive heart failure rats. Hypertension, 51 (4): 1096-1102, 2008.

20- AGARWAL D., WELSCH M.A., KELLER J.N. and FRANCIS J.: Chronic exercise modulates RAS components and improves balance between pro- and antiinflammatory cytokines in the brain of SHR. Basic. Res. Cardiol., 106 (6): 1069-1085, 2011.

21- DE ANGELIS K., WICHI R.B., JESUS W.R., MOREIRA E.D., MORRIS M., KRIEGE.R E.M. and IRIGOYEN M.C.: Exercise training changes autonomic cardiovascular balance in mice. J. Appl. Physiol., 96 (6): 2174-2178, 2004. 


\section{تأثير الرياضة وإيقافها على بعض القياسات الديناميكية

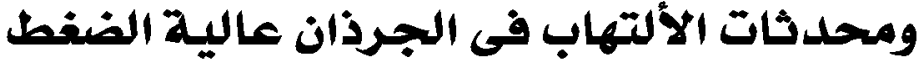

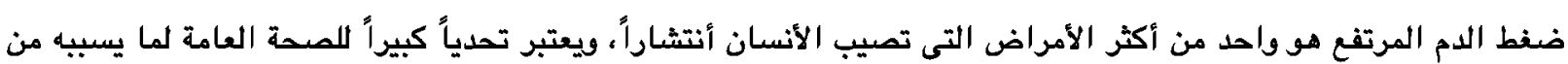

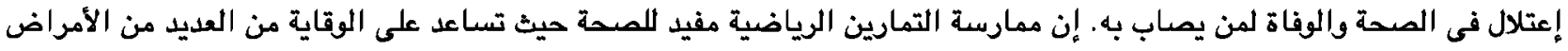

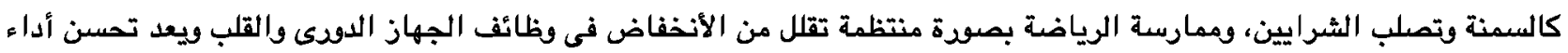

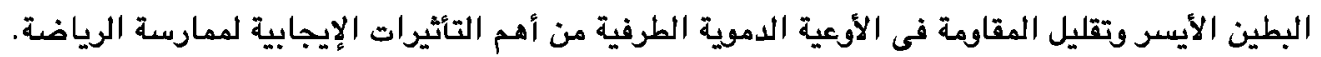

يهدف هذا البحث إلى دراسة تأثير الرياضة وإيقافها على بعض القياسات الديناميكية ومحدثات الألتهاب فى الجرذان ودود بعض

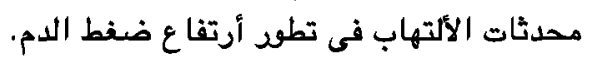

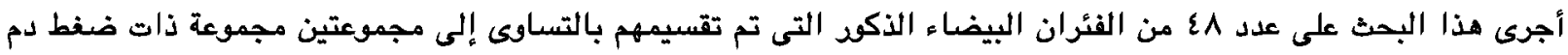

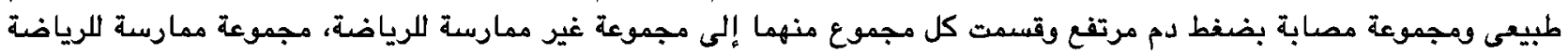
والمجموعة التى تم إيقاف الرياضة بهابة لضعا.

وكانت النتائج كالتالى : تصسنت كفاءة عضلة القلب فى المجموعة ذات ضفط الدمام الطبيعى الممارسة للرياضة وتحسنت قياسات

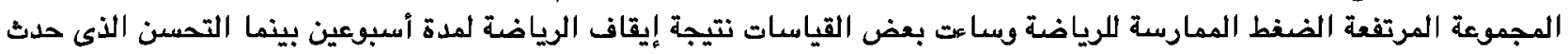
ضغط الدم أستمر بعد إيقاف الرياضة. 